\title{
Stabilization and improvement of a promising influenza antiviral: Making a PAIN PAINless
}

\author{
Aleksandar Antanasijevic ${ }^{1}$, Nicholas Hafeman ${ }^{2}$, Smanla Tundup ${ }^{3}$, Carolyn Kingsley ${ }^{1}$, Rama K \\ Mishra ${ }^{4}$, Lijun Rong ${ }^{5}$, Balaji Manicassamy ${ }^{3}$, Duncan Wardrop ${ }^{2}$ and Michael Caffrey ${ }^{{ }^{*}}$ \\ ${ }^{1}$ Department of Biochemistry \& Molecular Genetics \\ University of Illinois at Chicago \\ 900 S Ashland Ave \\ Chicago, IL 60607 \\ ${ }^{2}$ Department of Chemistry \\ University of Illinois at Chicago \\ 845 W Taylor St \\ Chicago, IL 60607 \\ ${ }^{3}$ Department of Microbiology and Immunology \\ University of Chicago \\ 920 E 58th St \\ Chicago, IL 60637 \\ ${ }^{4}$ Center for Molecular Innovation and Drug Discovery \\ Northwestern University \\ 2135 Sheridan Rd \\ Evanston, IL 60208 \\ ${ }^{5}$ Department of Microbiology \& Immunology \\ University of Illinois at Chicago \\ 835 S Wolcott \\ Chicago, IL 60612
}

*Corresponding Author

Supporting Information 


\section{Table of Contents}

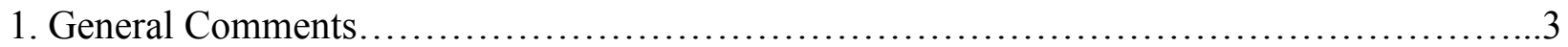

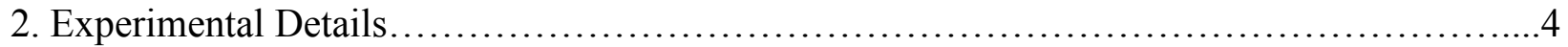

3. References.................................................................... 11

4. Spectral Data...................................................................... 12 


\section{General Comments}

All non-aqueous reactions were carried out in oven- or flame-dried glassware under an atmosphere of nitrogen, unless otherwise noted. All solvents were reagent grade. Triethylamine was distilled from calcium hydride, under nitrogen, and stored over potassium hydroxide. $N, N$ Dimethylformamide (DMF) was purchased from a commercial vendor and dried with freshly activated $4 \AA$ molecular sieves prior to use. All products were purified by flash column chromatography using silica gel 60 (mesh 230-400) either manually, or using a CombiFlash Rf+ chromatography system unless otherwise noted. All other reagents and starting materials were purchased from commercial vendors and used without further purification. All melting points were determined in open Pyrex capillaries with a Thomas Hoover Unimelt melting point apparatus and are uncorrected. ${ }^{1} \mathrm{H}$ and ${ }^{13} \mathrm{C}$ spectra were recorded on a Bruker Avance 400 (400 $\left.\mathrm{MHz}{ }^{1} \mathrm{H}, 100 \mathrm{MHz}{ }^{13} \mathrm{C}\right)$ or a Bruker Avance $500\left(500 \mathrm{MHz}{ }^{1} \mathrm{H}, 125 \mathrm{MHz}{ }^{13} \mathrm{C}\right)$ spectrometer. The purity of all compounds assayed was determined using analytical LC-MS (Agilent 1260 with an Agilent 6120 LC/MS quadropole MS, Supercosil LC 18 (250 mm x 4.6 mm, 5 micron) acetonitrile (unless otherwise noted), $2.00 \mathrm{~mL} / \mathrm{min}$ ) and was confirmed to be $\geq 95 \%$. 


\section{Experimental Details}

\section{Synthesis and Characterization of Compounds 12-21}

\section{1-(tert-Butyl)-2-methoxybenzene (12)}

To a stirred mixture of 2-tert-butylphenol (1.00 g, $6.66 \mathrm{mmol})$ and powdered, anhydrous potassium carbonate in acetone $(10 \mathrm{~mL})$ at room temperature was added dimethylsulfate $(0.950$ $\mathrm{mL}, 9.99 \mathrm{mmol}$ ) dropwise. The mixture was then heated at reflux for $15 \mathrm{~h}$, cooled to room temperature, and filtered through a plug of Celite. The filtrate was concentrated under reduced pressure and the residue purified by flash chromatography on silica gel to afford 1-(tert-butyl)-2methoxybenzene (12) (804 mg, $4.90 \mathrm{mmol}, 74 \%$ ) as a colorless liquid; $\mathrm{t}_{\mathrm{R}}$-LCMS: $2.72 \mathrm{~min}$ (100\%); ${ }^{1} \mathrm{H}$ NMR: $\left(500 \mathrm{MHz}, \mathrm{CDCl}_{3}\right) \delta: 7.33(\mathrm{~d}, J=8.0 \mathrm{~Hz}, 1 \mathrm{H}), 7.23(\mathrm{t}, J=8.0 \mathrm{~Hz}, 1 \mathrm{H})$, 6.94-6.91 (m, $2 \mathrm{H}), 3.89$ (s, $3 \mathrm{H}), 1.42$ (s, $9 \mathrm{H}) ;{ }^{13} \mathrm{C} \mathrm{NMR}\left(125 \mathrm{MHz}, \mathrm{CDCl}_{3}\right) \delta: 158.54,138.23$, $127.00,126.51,111.54,54.96,34.82,29.73$. 


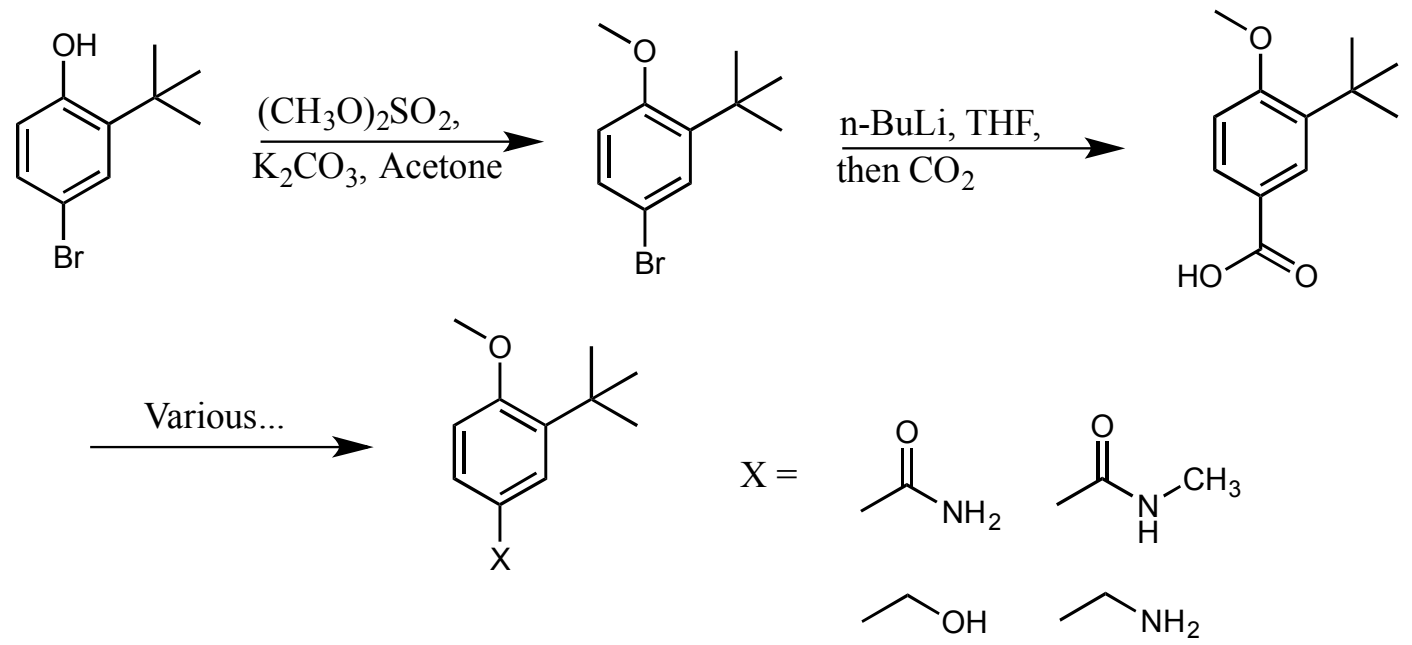

Scheme 1 .

\section{3-(tert-Butyl)-4-methoxybenzoic acid (13)}

Step 1. To a stirred mixture of 4-bromo-2-(tert-butyl)phenol (10) $(3.50 \mathrm{~g}, 15.3 \mathrm{mmol})$, powdered, anhydrous potassium carbonate $(8.45 \mathrm{~g}, 61.1 \mathrm{mmol})$ and 18-crown-6 (4.04 g, 15.3 $\mathrm{mmol})$ in acetone $(30 \mathrm{~mL})$ at room temperature was added dimethylsulfate $(2.31 \mathrm{~g}, 18.3 \mathrm{mmol})$ dropwise. The reaction mixture was stirred for $48 \mathrm{~h}$ then concentrated under reduced pressure and the residue dissolved in water $(100 \mathrm{~mL})$ and extracted with $\mathrm{Et}_{2} \mathrm{O}(3 \times 100 \mathrm{~mL})$. The combined organic extracts were concentrated under reduced pressure to afford 4-bromo-2-(tertbutyl)-1-methoxybenzene $(2.67 \mathrm{~g})$ as an oil which was used in Step 2 without further purification.

Step 2. To a stirred solution of the product obtained in Step $1(230 \mathrm{mg})$ in THF $(3 \mathrm{~mL})$ at $-78{ }^{\circ} \mathrm{C}$ under nitrogen was added $n$-butyllithium $(2.5 \mathrm{M}$ in hexanes, $0.450 \mathrm{~mL}, 1.14 \mathrm{mmol})$ dropwise via syringe. After $20 \mathrm{~min}$, a stream of carbon dioxide, generated by sublimation of dry ice through a drying tube, was bubbled into the reaction mixture with the aid of a cannula for $20 \mathrm{~min}$. The reaction was then quenched with saturated aqueous ammonium chloride and the mixture extracted with $\mathrm{Et}_{2} \mathrm{O}(3 \mathrm{x}, 30 \mathrm{~mL})$. The combined organic extracts were dried over sodium sulfate, filtered and concentrated under reduced pressure to afford a bright pink solid, which was purified 
by flash chromatography on silica gel to afford 3-(tert-butyl)-4-methoxybenzoic acid (13) (91 $\mathrm{mg}, 0.48 \mathrm{mmol}, 33 \%$ over two steps) as a white solid; mp 191-192 ${ }^{\circ} \mathrm{C}\left(193-194{ }^{\circ} \mathrm{C}\right) ;{ }^{1} \mathrm{t}_{\mathrm{R}}$-LCMS: $2.01 \mathrm{~min}(100 \%) ;{ }^{1} \mathrm{H}$ NMR: $\left(400 \mathrm{MHz}, \mathrm{CDCl}_{3}\right) \delta: 8.90(\mathrm{~d}, J=2.0 \mathrm{~Hz}, 1 \mathrm{H}), 8.02(\mathrm{dd}, J=8.4$, $2.0 \mathrm{~Hz}, 1 \mathrm{H}), 6.94(\mathrm{~d}, J=8.4 \mathrm{~Hz}, 1 \mathrm{H}) 3.94(\mathrm{~s}, 3 \mathrm{H}), 1.43(\mathrm{~s}, 9 \mathrm{H}) ;{ }^{13} \mathrm{C} \mathrm{NMR}\left(100 \mathrm{MHz}, \mathrm{CDCl}_{3}\right)$ $\delta: 172.99,163.46,138.63,130.69,129.40,121.38,111.26,77.10,55.60,35.35,29.91$.

\section{(3-(tert-Butyl)-4-methoxyphenyl)methanol (14)}

To a stirred suspension of lithium aluminum hydride $(11 \mathrm{mg}, 0.29 \mathrm{mmol})$ in THF $(0.250 \mathrm{~mL})$ at $0{ }^{\circ} \mathrm{C}$ under nitrogen was added solution of 3-(tert-butyl)-4-methoxybenzoic acid (13) (40 mg, $0.19 \mathrm{mmol})$ in THF $(0.100 \mathrm{~mL})$ dropwise via syringe. After removing the cooling bath, the mixture was stirred at room temperature for $16 \mathrm{~h}$. The mixture was then cooled to $0{ }^{\circ} \mathrm{C}$ and cautiously quenched with saturated aqueous sodium sulfate. The resulting light grey precipitate was removed by filtration through a plug of Celite, which was subsequently washed with $\mathrm{CH}_{2} \mathrm{Cl}_{2}$. The combined filtrates were dried over sodium sulfate, filtered, concentrated under reduced pressure and the residue purified by flash chromatography on silica gel to afford (3-(tertbutyl)-4-methoxyphenyl)methanol (14) (33 $\mathrm{mg}, 0.17 \mathrm{mmol}, 88 \%)$ as a colorless oil; $\mathrm{t}_{\mathrm{R}}$-LCMS: $1.95 \mathrm{~min}(100 \%) ;{ }^{1} \mathrm{H} \mathrm{NMR}:\left(500 \mathrm{MHz}, \mathrm{CDCl}_{3}\right) \delta: 7.31(\mathrm{~d}, J=2.0 \mathrm{~Hz}, 1 \mathrm{H}), 7.22(\mathrm{dd}, J=8.5$, $2.0 \mathrm{~Hz}, 1 \mathrm{H}), 6.89$ (d, $J=8.5 \mathrm{~Hz}, 1 \mathrm{H}), 4.37$ (s, $2 \mathrm{H}), 3.87$ (s, 3H), 1.62 (m, 1H), 1.41 (s, $9 \mathrm{H})$; ${ }^{13} \mathrm{C}$ NMR: (125 MHz, $\left.\mathrm{CDCl}_{3}\right) \delta: 158.23,138.48,132.45,126.10$ (x2), 111.57, 65.60, 55.14, $34.85,29.67$

3-(tert-Butyl)-4-methoxybenzamide (15) was prepared via an adapted literature procedure: ${ }^{2}$

To a stirred solution of 3-(tert-butyl)-4-methoxybenzoic acid (13) (100 mg, $0.480 \mathrm{mmol}) \mathrm{CH}_{2} \mathrm{Cl}_{2}$ $(5 \mathrm{~mL})$ at room temperature was sequentially added oxalyl chloride $(305 \mathrm{mg}, 2.4 \mathrm{mmol})$ and a single drop of DMF via syringe. The mixture was stirred for $2 \mathrm{~h}$, then concentrated under reduced pressure and the residue dissolved in $\mathrm{CH}_{2} \mathrm{Cl}_{2}(0.5 \mathrm{~mL})$. With the aid of a syringe, this solution was added to a stirred solution of hexamethyldisilazane (233 mg, $1.44 \mathrm{mmol})$ in $\mathrm{CH}_{2} \mathrm{Cl}_{2}$ $(5 \mathrm{~mL})$ at $0{ }^{\circ} \mathrm{C}$. After warming to room temperature, this mixture was stirred for $15 \mathrm{~h}$ then quenched with water $(0.5 \mathrm{~mL})$ and the mixture extracted with $\mathrm{Et}_{2} \mathrm{O}(3 \times 50 \mathrm{~mL})$. The combined organic extracts were washed with brine, dried over sodium sulfate, filtered and concentrated under reduced pressure to afford a white solid, which was purified by flash chromatography on 
silica gel to afford 3-(tert-butyl)-4-methoxybenzamide (15) (80 mg, $0.39 \mathrm{mmol}, 80 \%)$ as a white solid; mp 160-162 ${ }^{\circ} \mathrm{C}$; $\mathrm{t}_{\mathrm{R}}$-LCMS: $1.61 \mathrm{~min}(100 \%) ;{ }^{1} \mathrm{H}$ NMR: $\left(500 \mathrm{MHz}, \mathrm{CDCl}_{3}\right) \delta: 7.81(\mathrm{~d}, J=$ $2.5 \mathrm{~Hz}, 1 \mathrm{H}), 7.67(\mathrm{dd}, J=8.5,2.0 \mathrm{~Hz}, 1 \mathrm{H}), 6.90$ (d, $J=8.5 \mathrm{~Hz}, 1 \mathrm{H}), 6.04$ (br s, $2 \mathrm{H}), 3.91$ (s, 3 $\mathrm{H}), 1.41(\mathrm{~s}, 9 \mathrm{H}) ;{ }^{13} \mathrm{C}$ NMR: $\left(125 \mathrm{MHz}, \mathrm{CDCl}_{3}\right) \delta: 169.70,161.54,138.39,126.68,126.35$, $125.05,110.88,55.15,34.98,29.51$

\section{3-(tert-Butyl)-4-methoxy- $N$-methylbenzamide (16)}

To a stirred solution of 3-(tert-butyl)-4-methoxybenzoic acid (13) (60 mg, $\left.0.29 \mathrm{mmol}^{2}\right)$ and $\mathrm{Et}_{3} \mathrm{~N}$ $(65 \mu \mathrm{L}, 0.46 \mathrm{mmol})$ in $\mathrm{CH}_{2} \mathrm{Cl}_{2}(0.4 \mathrm{~mL})$ at room temperature was added EDC (99.4 mg, 0.519 mmol), $N$-methoxylamine hydrochloride $(31.1 \mathrm{mg}, 0.46 \mathrm{mmol})$, and DMAP (3.5 $\mathrm{mg}, 0.03$ $\mathrm{mmol})$. The mixture was stirred for $15 \mathrm{~h}$ at room temperature, then quenched with aqueous $\mathrm{HCl}$ $(1 \mathrm{~N}, 0.5 \mathrm{~mL})$ and the mixture extracted with $\mathrm{CH}_{2} \mathrm{Cl}_{2}(3 \times 20 \mathrm{~mL})$. The combined organic extracts were washed with brine, dried over sodium sulfate, filtered, and concentrated under reduced pressure to afford a beige solid, which was purified by flash chromatography on silica gel to afford 3-(tert-butyl)-4-methoxy- $N$-methylbenzamide (16) (45 $\mathrm{mg}, 0.22 \mathrm{mmol}, 76 \%)$ as a white solid; $\mathrm{mp} 81-82{ }^{\circ} \mathrm{C}$; $\mathrm{t}_{\mathrm{R}}$-LCMS: $1.76 \mathrm{~min}(100 \%) ;{ }^{1} \mathrm{H} \mathrm{NMR}:\left(500 \mathrm{MHz}, \mathrm{CDCl}_{3}\right) \delta: 7.75$ (d, $J=2.5 \mathrm{~Hz}, 1 \mathrm{H}), 7.61(\mathrm{dd}, J=8.5,2.0 \mathrm{~Hz}, 1 \mathrm{H}), 6.87$ (d, $J=8.5 \mathrm{~Hz}, 1 \mathrm{H}), 6.28$ (br s, $1 \mathrm{H}), 3.89$ $(\mathrm{s}, 3 \mathrm{H}), 3.00(\mathrm{~d}, J=4 \mathrm{~Hz}, 3 \mathrm{H}), 1.39$ (s, $9 \mathrm{H}) ;{ }^{13} \mathrm{C} \mathrm{NMR}\left(125 \mathrm{MHz}, \mathrm{CDCl}_{3}\right) \delta: 168.46,160.99$, $138.24,126.37,125.98,125.74,110.87,55.11,34.96,29.52,26.79$

\section{(3-(tert-Butyl)-4-methoxyphenyl)methanamine (17)}

To a stirred suspension of lithium aluminum hydride $(54.9 \mathrm{mg}, 1.45 \mathrm{mmol})$ in THF (2 mL) at 0 ${ }^{\circ} \mathrm{C}$ under nitrogen was added a solution of 3-(tert-butyl)-4-methoxybenzamide (15) (30.0 mg, $0.145 \mathrm{mmol})$ in THF $(2.0 \mathrm{~mL})$ dropwise. The cooling bath was then removed and the mixture heated at reflux for $15 \mathrm{~h}$. After cooling to $0{ }^{\circ} \mathrm{C}$, the mixture was quenched cautiously with a saturated aqueous solution of sodium sulfate. The resulting grey precipitate was filtered through a bed of Celite, which was subsequently washed with $\mathrm{CH}_{2} \mathrm{Cl}_{2}$. The combined filtrates were then concentrated under reduced pressure and purified by flash chromatography on silica gel to afford (3-(tert-butyl)-4-methoxyphenyl)methanamine (17) (20.0 $\mathrm{mg}, 0.103 \mathrm{mmol} 72 \%)$ as a colorless oil; $\mathrm{t}_{\mathrm{R}}$-LCMS: $0.97 \mathrm{~min}(97 \%) ;{ }^{1} \mathrm{H}$ NMR: $\left(500 \mathrm{MHz}, \mathrm{CDCl}_{3}\right) \delta: 7.24$ (d, J=2 Hz, $\left.1 \mathrm{H}\right), 7.16$ (dd, $J=8.0 \mathrm{~Hz}, 2 \mathrm{~Hz}, 1 \mathrm{H}), 6.88(\mathrm{~d}, J=8.0 \mathrm{~Hz}, 1 \mathrm{H}), 3.86(\mathrm{~s}, 3 \mathrm{H}), 3.83$ (s, $2 \mathrm{H}), 1.70$ (br s, $2 \mathrm{H})$, 
1.41 (s, 9H); ${ }^{13} \mathrm{C}$ NMR: (125 MHz, $\left.\mathrm{CDCl}_{3}\right) \delta: 157.49,138.33,134.81,125.78,125.51,111.63$, $55.14,46.29,34.84,29.73$.

4-(Benzyloxy)-2-(tert-butyl)phenol was prepared via an adapted literature procedure: ${ }^{3}$

To a stirred solution of tert-butylhydroquinone $(5.00 \mathrm{~g}, 30.1 \mathrm{mmol})$ in methanol $(15.0 \mathrm{~mL})$ was added a solution of benzyl bromide $(3.71 \mathrm{~mL}, 31.2 \mathrm{mmol})$ in hexanes $(31 \mathrm{~mL})$ and diethyl ether $(5 \mathrm{~mL})$. To this biphasic mixture was added a solution of sodium hydroxide $(1.4 \mathrm{~g}, 35.0 \mathrm{mmol})$ in water $(12 \mathrm{~mL})$. The reaction mixture was then stirred for $15 \mathrm{~h}$ under nitrogen, followed by $2 \mathrm{~h}$ at reflux. After cooling to room temperature, the mixture was titrated with aqueous $\mathrm{HCl}$ to $\mathrm{pH} 7$ and the phases separated. The organic (upper) phase was washed with water $(1 \times 100 \mathrm{~mL})$ and then brine $(1 \times 100 \mathrm{~mL})$, dried over anhydrous sodium sulfate, and concentrated under reduced pressure to afford an orange oil which was purified by flash chromatography to afford 4(benzyloxy)-2-(tert-butyl)phenol $(4.3 \mathrm{~g}, 16.8 \mathrm{mmol}, 56 \%)$ as a white solid; $\mathrm{mp} 84-85^{\circ} \mathrm{C}(87.5$ 89); ${ }^{2}{ }^{1} \mathrm{H}$ NMR: (500 MHz, $\left.\mathrm{CDCl}_{3}\right) \delta:$ 7.48-7.46 (m, $\left.2 \mathrm{H}\right), 7.43-7.40$ (m, $\left.2 \mathrm{H}\right), 7.37-7.34$ (m, 1 H), $6.98(\mathrm{~d}, \mathrm{~J}=3.0 \mathrm{~Hz}, 1 \mathrm{H}), 6.70(\mathrm{dd}, \mathrm{J}=8.5 \mathrm{~Hz}, 3.0 \mathrm{~Hz}, 1 \mathrm{H}), 6.61(\mathrm{~d}, \mathrm{~J}=8.5 \mathrm{~Hz}, 1 \mathrm{H}), 5.03(\mathrm{~s}$, $2 \mathrm{H}), 4.54$ (s, $1 \mathrm{H}), 1.43$ (s, $9 \mathrm{H}) ;{ }^{13} \mathrm{C}$ NMR: $\left(125 \mathrm{MHz}, \mathrm{CDCl}_{3}\right) \delta: 152.73,148.37,137.58$, $137.39,128.55,127.89,127.61,116.77,115.21,111.67,70.73,34.71,29.49$.

Representative procedure for the preparation of O-alkyl derivatives 18-21
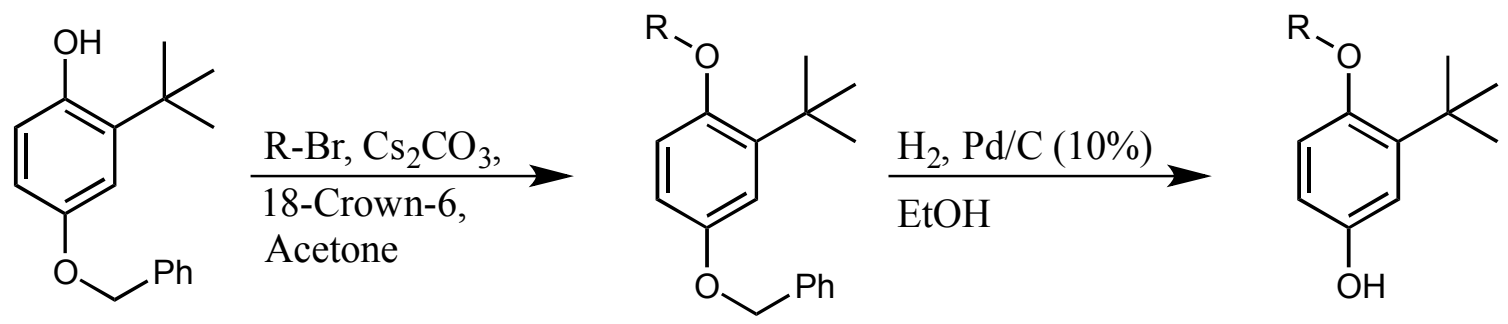

Scheme 2 .

\section{4-(Benzyloxy)-2-(tert-butyl)-1-isopropoxybenzene}

A stirred mixture of 4-(benzyloxy)-2-(tert-butyl)phenol (200 mg, $0.780 \mathrm{mmol})$, powdered, anhydrous cesium carbonate $(508 \mathrm{mg}, 1.56 \mathrm{mmol}), 18$-crown-6 $(41 \mathrm{mg}, 0.156 \mathrm{mmol})$ and 
isopropyl bromide $(147 \mu \mathrm{L}, 1.56 \mathrm{mmol})$ in acetone $(1.5 \mathrm{~mL})$ was heated at reflux for $6 \mathrm{~h}$. After cooling to room temperature, the mixture was filtered through a plug of Celite and the filtrate concentrated under reduced pressure. The resulting residue was purified by flash chromatography on silica gel to afford 4-(benzyloxy)-2-(tert-butyl)-1-isopropoxybenzene (90.0 $\mathrm{mg}, 0.302 \mathrm{mmol}, 39 \%)$ as a white solid $\mathrm{mp} 76-7{ }^{\circ} \mathrm{C}$; ${ }^{1} \mathrm{H}$ NMR: (400 MHz, $\left.\mathrm{CDCl}_{3}\right) \delta$ : 7.51-7.50 (m, 2 H), 7.46-7.42 (m, 2 H), 7.39-7.37 (m, 1 H), 7.05-7.04 (m, 1 H), 6.80-6.79 (m, 2 H), 5.06 (s, $2 \mathrm{H}), 4.64$ (sep, J = 6.0 Hz, $1 \mathrm{H}), 1.44(\mathrm{~s}, 9 \mathrm{H}), 1.42(\mathrm{~d}, \mathrm{~J}=6.0 \mathrm{~Hz}) ;{ }^{13} \mathrm{C}$ NMR: (100 MHz, $\left.\mathrm{CDCl}_{3}\right) \delta: 152.31,150.93,140.33,138.00,128.96,128.26,128.05,115.86,112.97,111.38$, $71.06,69.15,35.41,30.19,22.50$.

\section{3-(tert-Butyl)-4-isopropoxyphenol (19)}

A stirred mixture of 4-(benzyloxy)-2-(tert-butyl)-1-isopropoxybenzene (90.0 mg, $0.302 \mathrm{mmol}$ ) and $10 \%$ palladium on activated carbon $(25 \mathrm{mg})$ in $\mathrm{EtOH}(2 \mathrm{~mL})$ was evacuated and back-filled with nitrogen three times and then placed under an atmosphere of hydrogen (balloon). After $6 \mathrm{~h}$, the flask was evacuated and back-filled with nitrogen three times, and the mixture filtered through a plug of Celite. The filtrate was concentrated under reduced pressure, and the resulting residue purified by flash chromatography on silica gel to afford 3-(tert-butyl)-4isopropoxyphenol (18) $(45.0 \mathrm{mg}, 0.216 \mathrm{mmol}, 72 \%)$ as a white solid; $\mathrm{mp} 51-52{ }^{\circ} \mathrm{C}$; $\mathrm{t}_{\mathrm{R}}-\mathrm{LCMS}$ : $2.37 \min (99 \%)$; ${ }^{1} \mathrm{H}$ NMR: $\left(400 \mathrm{MHz}, \mathrm{CDCl}_{3}\right) \delta: 6.84(\mathrm{~d}, \mathrm{~J}=2.8 \mathrm{~Hz}, 1 \mathrm{H}), 6.73(\mathrm{~d}, \mathrm{~J}=8.4 \mathrm{~Hz}, 1$ H), 6.64 (dd, J = 8.4, $2.8 \mathrm{~Hz}, 1 \mathrm{H}$ ), 4.72 (br s, $1 \mathrm{H}$ ), 4.59 (sep, J = 6.0 Hz, 1 H), 1.39 (s, 9 H), $1.38(\mathrm{~d}, \mathrm{~J}=6.0 \mathrm{~Hz}, 6 \mathrm{H}) ;{ }^{13} \mathrm{C}$ NMR: $\left(100 \mathrm{MHz}, \mathrm{CDCl}_{3}\right) \delta: 150.66,148.55,140.36,115.04$, $113.41,112.74,69.15,35.23,30.11,22.44$.

\section{4-(Benzyloxy)-2-(tert-butyl)-1-ethoxybenzene}

Yield 47\%; yellow solid; mp 82-83 ${ }^{\circ} \mathrm{C}$; ${ }^{1} \mathrm{H}$ NMR: $\left(500 \mathrm{MHz}, \mathrm{CDCl}_{3}\right) \delta$ : 7.49-7.48 (m, $\left.2 \mathrm{H}\right)$, 7.44-7.41 (m, 2 H), 7.37-7.36 (m, 1 H), 7.01 (d, J = 2.8 Hz, 1 H), 6.81 (d, J = 8.8 Hz, 1 H), 6.78 (dd, J = 8.8, $2.8 \mathrm{~Hz}, 1 \mathrm{H}), 5.04$ (s, $2 \mathrm{H}), 4.04$ (q, J = 6.8 Hz, $2 \mathrm{H}$ ), 1.48 (t, J = 6.8 Hz, $3 \mathrm{H}$ ), 1.42 (s, $9 \mathrm{H}) ;{ }^{13} \mathrm{C}$ NMR $\left(125 \mathrm{MHz}, \mathrm{CDCl}_{3}\right) \delta: 152.35,152.30,139.74,137.51,128.54,127.86$, $127.62,115.23,112.60,110.96,70.61,63.86,34.98,29.71,15.10$.

\section{3-(tert-Butyl)-4-ethoxyphenol (18)}


Yield 85\%; white solid; $\mathrm{mp} 46-47{ }^{\circ} \mathrm{C}$; $\mathrm{t}_{\mathrm{R}}$-LCMS: $2.20 \mathrm{~min}(100 \%) ;{ }^{1} \mathrm{H}$ NMR: $\left(500 \mathrm{MHz}, \mathrm{CDCl}_{3}\right)$ $\delta: 6.83(\mathrm{~d}, \mathrm{~J}=3.0 \mathrm{~Hz}, 1 \mathrm{H}), 6.76(\mathrm{~d}, \mathrm{~J}=8.5 \mathrm{~Hz}, 1 \mathrm{H}), 6.65(\mathrm{dd}, \mathrm{J}=8.5,3.0 \mathrm{~Hz}, 1 \mathrm{H}), 4.76(\mathrm{~s}, 1$ $\mathrm{H}), 4.02(\mathrm{q}, \mathrm{J}=6.8 \mathrm{~Hz}, 2 \mathrm{H}), 1.47(\mathrm{t}, \mathrm{J}=6.8 \mathrm{~Hz}, 3 \mathrm{H}), 1.40(\mathrm{~s}, 9 \mathrm{H}) ;{ }^{13} \mathrm{C} \mathrm{NMR}(125 \mathrm{MHz}$, $\left.\mathrm{CDCl}_{3}\right) \delta: 152.08,148.65,139.83,114.43,113.21,112.48,63.99,34.84,29.68,15.08$.

\section{4-(Benzyloxy)-2-(tert-butyl)-1-isobutoxybenzene}

Yield 62\%; colorless oil; ${ }^{1} \mathrm{H}$ NMR: $\left(400 \mathrm{MHz}, \mathrm{CDCl}_{3}\right) \delta$ : 7.55-7.44 (m, $\left.2 \mathrm{H}\right)$, 7.50-7.46 (m, 2 H), 7.43-7.39 (m, $1 \mathrm{H}), 7.11-7.10(\mathrm{~m}, 1 \mathrm{H}), 6.88-6.83(\mathrm{~m}, 2 \mathrm{H}), 5.10(\mathrm{~s}, 2 \mathrm{H}), 3.81$ (d, J = 6.6 Hz, $2 \mathrm{H}), 2.25(\mathrm{sep}, \mathrm{J}=6.6 \mathrm{~Hz}, 1 \mathrm{H}), 1.51$ (s, $9 \mathrm{H}), 1.19$ (d, J = 6.6 Hz, $6 \mathrm{H}) ;{ }^{13} \mathrm{C} \mathrm{NMR}(100 \mathrm{MHz}$, $\left.\mathrm{CDCl}_{3}\right) \delta: 152.90,152.72,139.91,138.01,129.00,128.30,128.07,115.85,112.46,111.42$, 75.31, 71.09, 35.50, 30.28, 29.11, 20.28.

\section{3-(tert-Butyl)-4-isobutoxyphenol (20)}

Yield 86\%; colorless, low melting solid; $\mathrm{t}_{\mathrm{R}}$-LCMS: $2.58 \mathrm{~min}(100 \%)$; ${ }^{1} \mathrm{H}$ NMR: (500 MHz, $\left.\mathrm{CDCl}_{3}\right) \delta: 6.87(\mathrm{~d}, \mathrm{~J}=3.0 \mathrm{~Hz}, 1 \mathrm{H}), 6.76(\mathrm{~d}, \mathrm{~J}=8.5 \mathrm{~Hz}, 1 \mathrm{H}), 6.67(\mathrm{dd}, \mathrm{J}=8.5,3.0 \mathrm{~Hz}, 1 \mathrm{H})$, $5.15(\mathrm{~m}, 1 \mathrm{H}), 3.74(\mathrm{~d}, \mathrm{~J}=6.8 \mathrm{~Hz}, 2 \mathrm{H}), 2.19(\mathrm{sep}, \mathrm{J}=6.8 \mathrm{~Hz}, 1 \mathrm{H}), 1.48$ (s, $9 \mathrm{H}), 1.12$ (d, $6 \mathrm{H}, \mathrm{J}$ $=6.8 \mathrm{~Hz}) ;{ }^{13} \mathrm{C} \mathrm{NMR}\left(125 \mathrm{MHz}, \mathrm{CDCl}_{3}\right) \delta: 152.23,148.48 .114 .61,112.55,112.51,74.93,34.89$. 29.76, 28.64. 19.79.

\section{4-(Benzyloxy)-1-(sec-butoxy)-2-(tert-butyl)benzene}

Yield 25\%; white soild; mp 59-60 ${ }^{\circ} \mathrm{C}$; ${ }^{1} \mathrm{H}$ NMR: (500 MHz, $\left.\mathrm{CDCl}_{3}\right) \delta$ : 7.49-7.47 (m, $\left.2 \mathrm{H}\right), 7.43-$ $7.42(\mathrm{~m}, 2 \mathrm{H}), 7.36-7.34(\mathrm{~m}, 1 \mathrm{H}), 7.02-7.01(\mathrm{~m}, 1 \mathrm{H}), 6.77-6.76(\mathrm{~m}, 2 \mathrm{H}), 5.03(\mathrm{~s}, 2 \mathrm{H}), 4.41$ $(\mathrm{sex}, \mathrm{J}=6.5 \mathrm{~Hz}, 1 \mathrm{H}), 1.88-1.81(\mathrm{~m}, 1 \mathrm{H}), 1.75-1.66(\mathrm{~m}, 1 \mathrm{H}), 1.41$ (s, $9 \mathrm{H}), 1.32(\mathrm{~d}, \mathrm{~J}=6.5 \mathrm{~Hz}$, $3 \mathrm{H}), 1.05(\mathrm{t}, \mathrm{J}=6.5 \mathrm{~Hz}, 3 \mathrm{H}) ;{ }^{13} \mathrm{C} \mathrm{NMR}\left(125 \mathrm{MHz}, \mathrm{CDCl}_{3}\right) \delta: 151.79,150.57,139.85,137.58$, $128.52,127.83,127.61,115.48,112.23,110.89,73.49,70.63,35.02,29.77,29.24,18.82,10.22$.

\section{4-(sec-Butoxy)-3-(tert-butyl)phenol (21)}

Yield 80\%; colorless oil; $\mathrm{t}_{\mathrm{R}}-\mathrm{LCMS}: 2.55 \min (95 \%) ;{ }^{1} \mathrm{H}$ NMR: $\left(400 \mathrm{MHz}, \mathrm{CDCl}_{3}\right) \delta: 6.84(\mathrm{~d}, \mathrm{~J}=$ $2.5 \mathrm{~Hz}, 1 \mathrm{H}), 6.72$ (d, J = 8.6 Hz, $1 \mathrm{H}), 6.64$ (dd, J = 8.6, $2.5 \mathrm{~Hz}, 1 \mathrm{H}), 4.52$ (br s, $1 \mathrm{H}), 4.38$ (sex, $\mathrm{J}=5.8 \mathrm{~Hz}, 1 \mathrm{H}), 1.88-1.78(\mathrm{~m}, 1 \mathrm{H}), 1.74-1.64(\mathrm{~m}, 1 \mathrm{H}), 1.39(\mathrm{~s}, 9 \mathrm{H}), 1.30(\mathrm{~d}, \mathrm{~J}=5.8 \mathrm{~Hz}, 3 \mathrm{H})$, 
$1.03(\mathrm{t}, \mathrm{J}=7.6,3 \mathrm{H}) ;{ }^{13} \mathrm{C} \mathrm{NMR}\left(125 \mathrm{MHz}, \mathrm{CDCl}_{3}\right) \delta: 150.32,148.07,139.874,114.71,112.71$, $112.32,73.52,34.88,29.73,29.23,18.79,10.01$.

\section{References}

1. Carpenter, M.; Easter, W.; Wood, T. J. Org. Chem. 1951, 586-617

2. Pellegata, R.; Italia, A.; Villa, M.; Palmisano, G.; Lesma, G. Synthesis 1985, 517-519

3. Welbes, L.; Scarrow, R. J. Chem. Soc., Chem. Commun. 2004, 2544-2545

\section{Spectral Data}



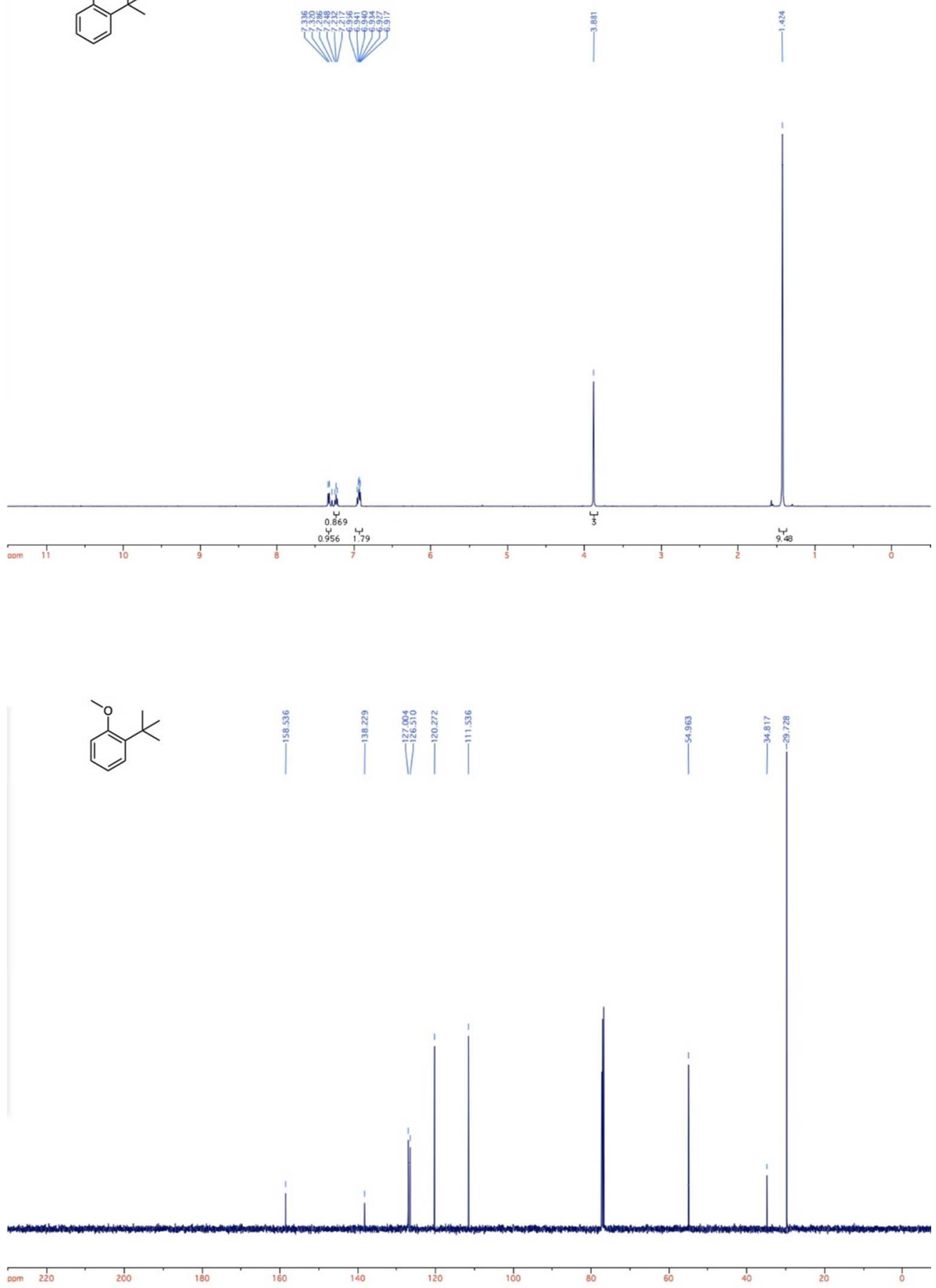

S.I.12 

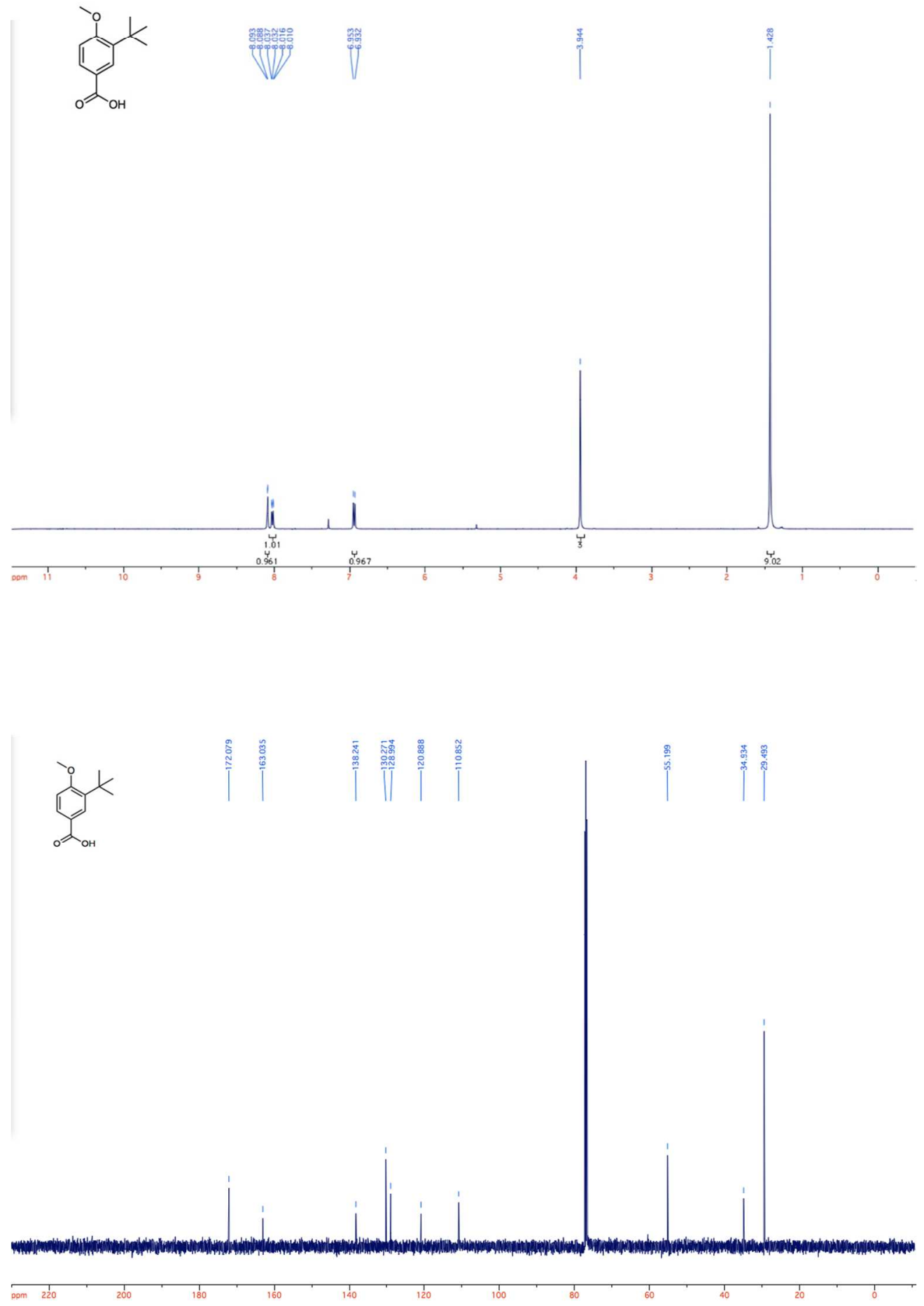

S.I.13 

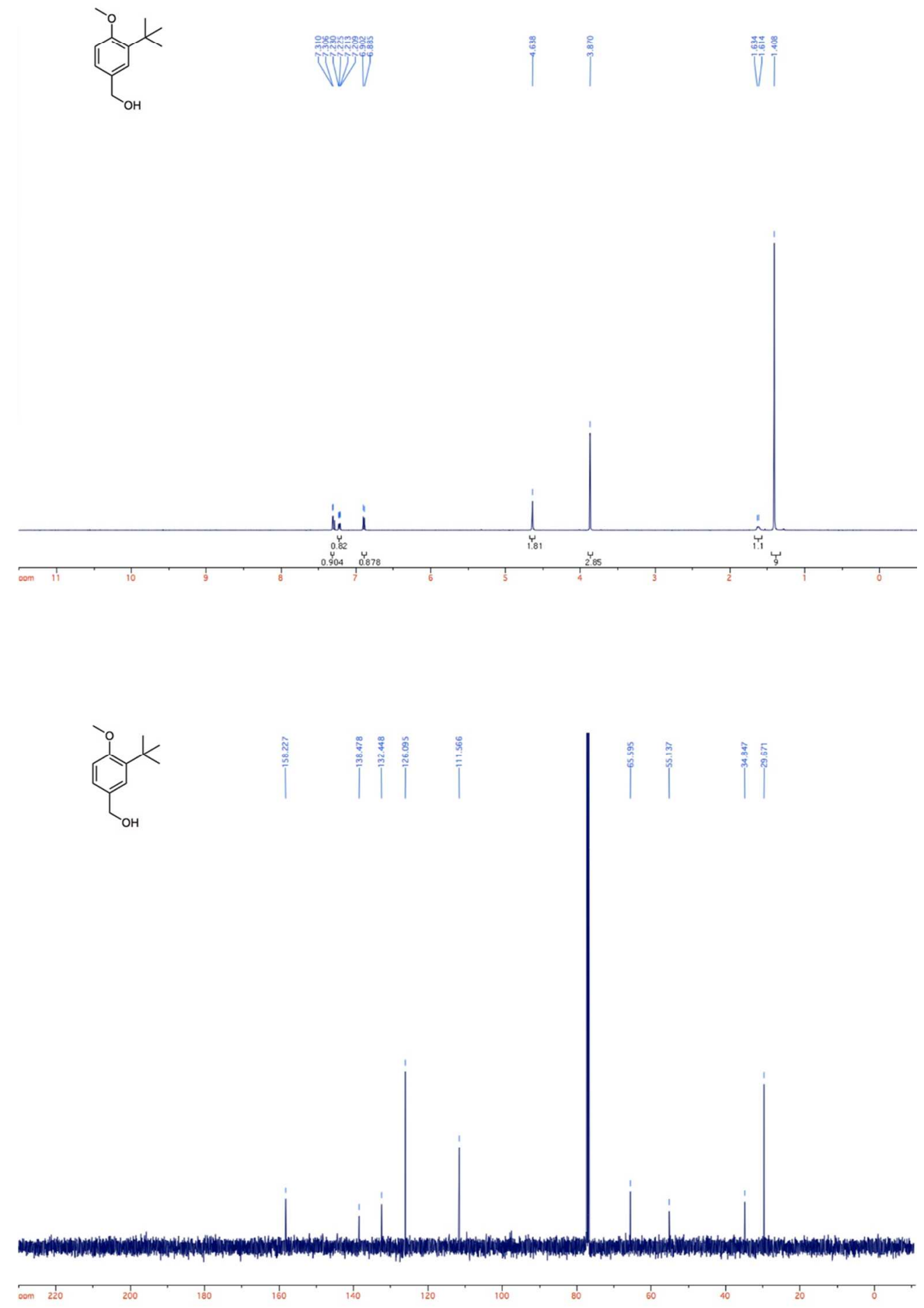

S.I.14 

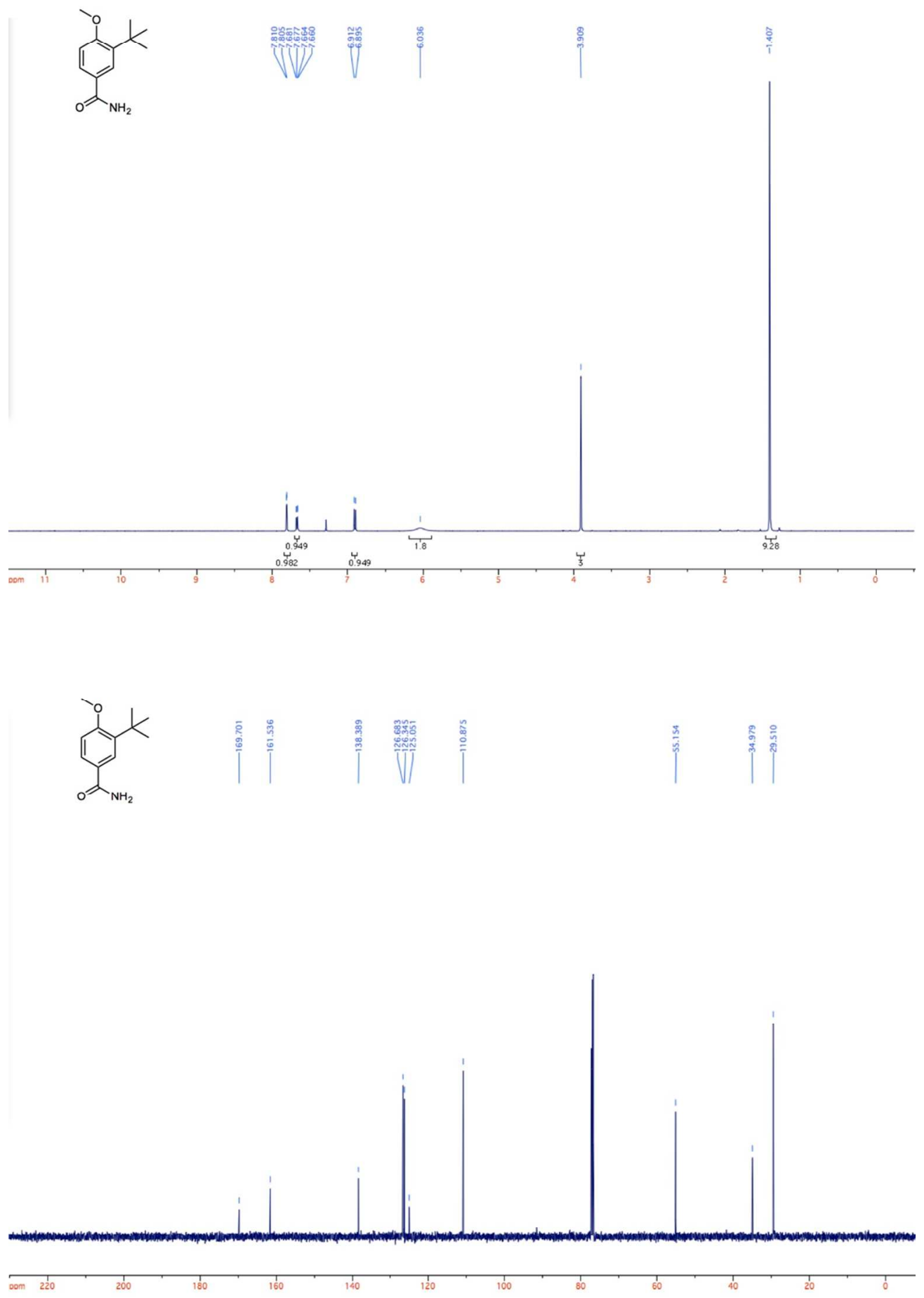

S.I.15 

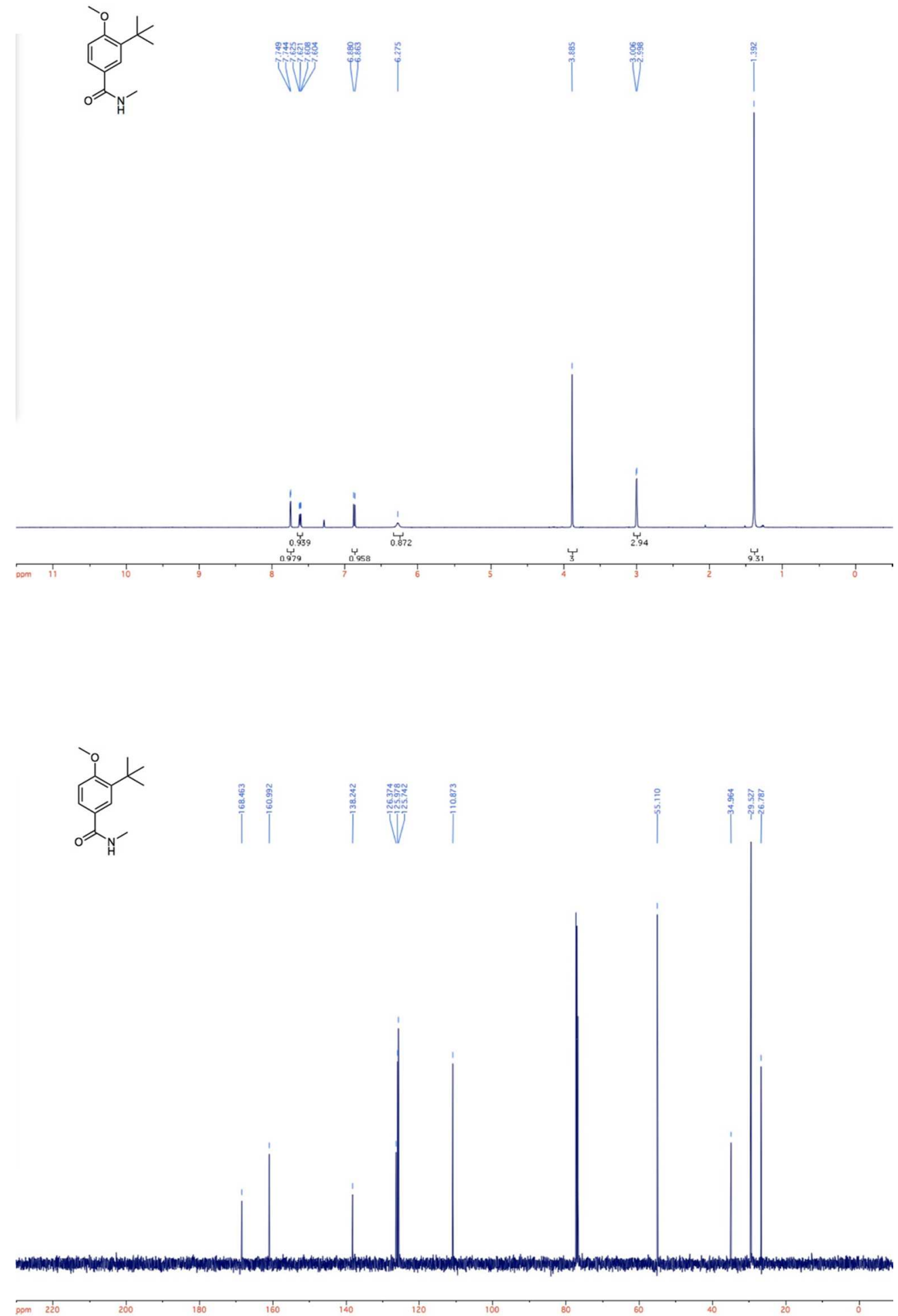

S.I.16 

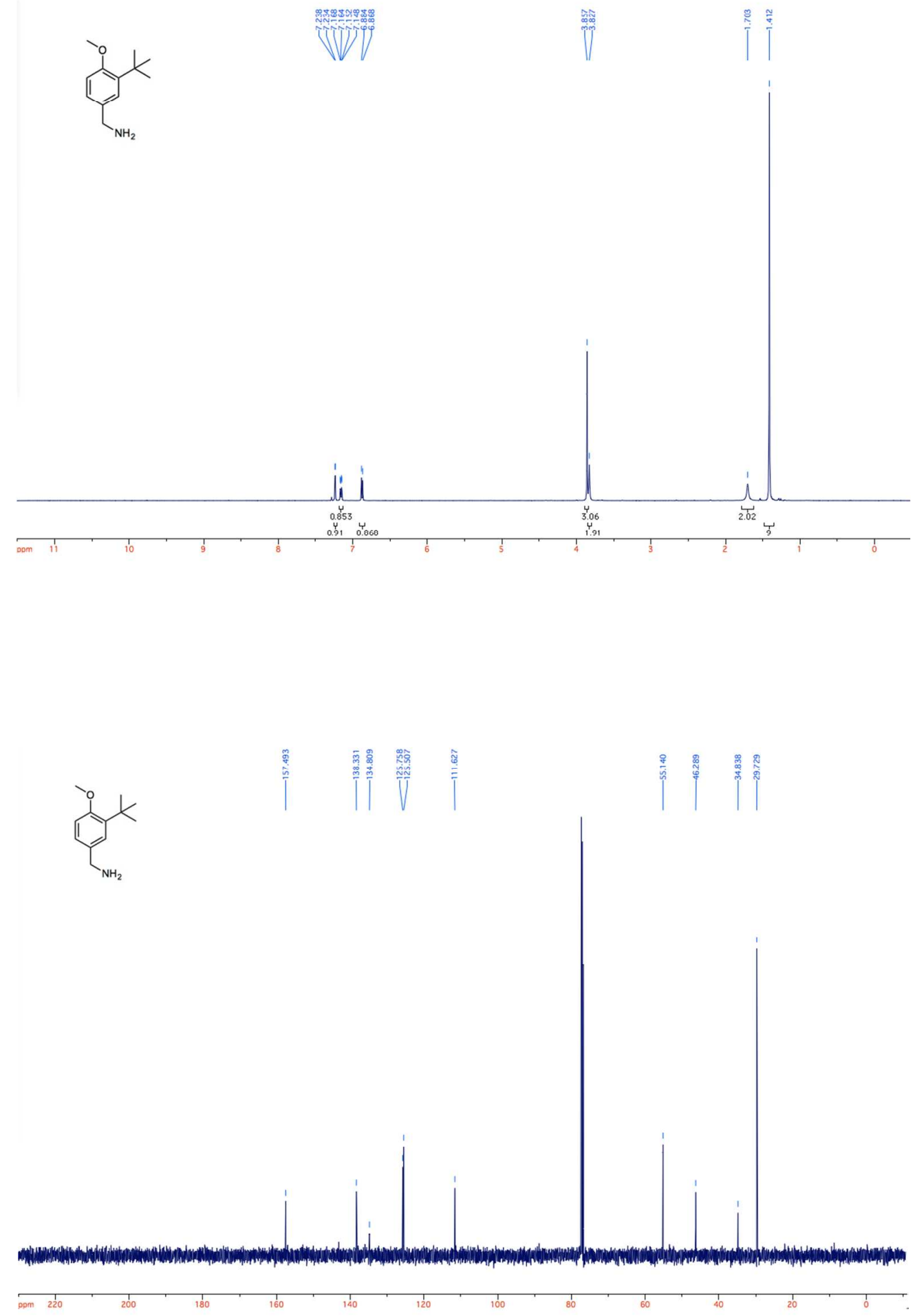

S.I.17 

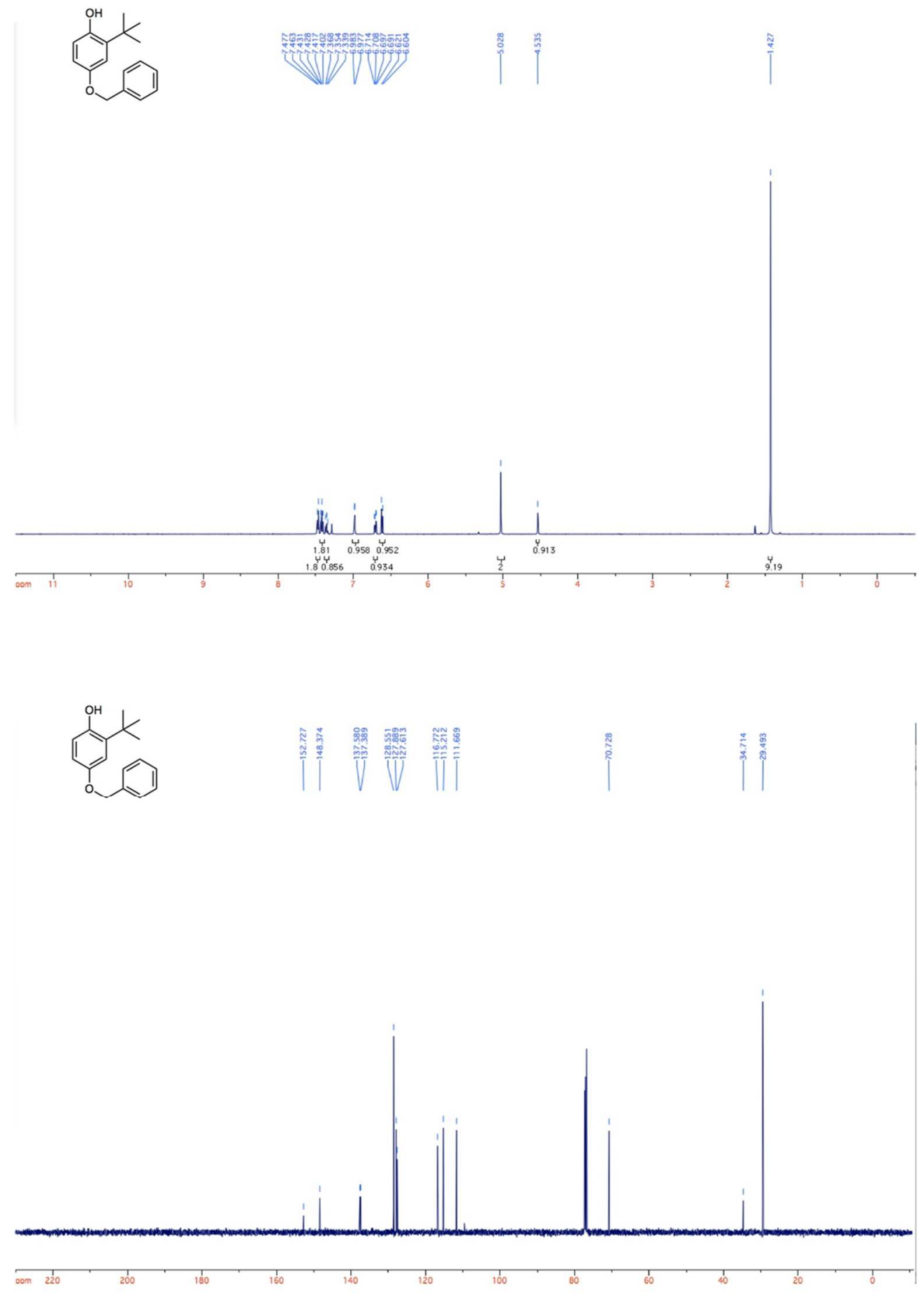

S.I.18 

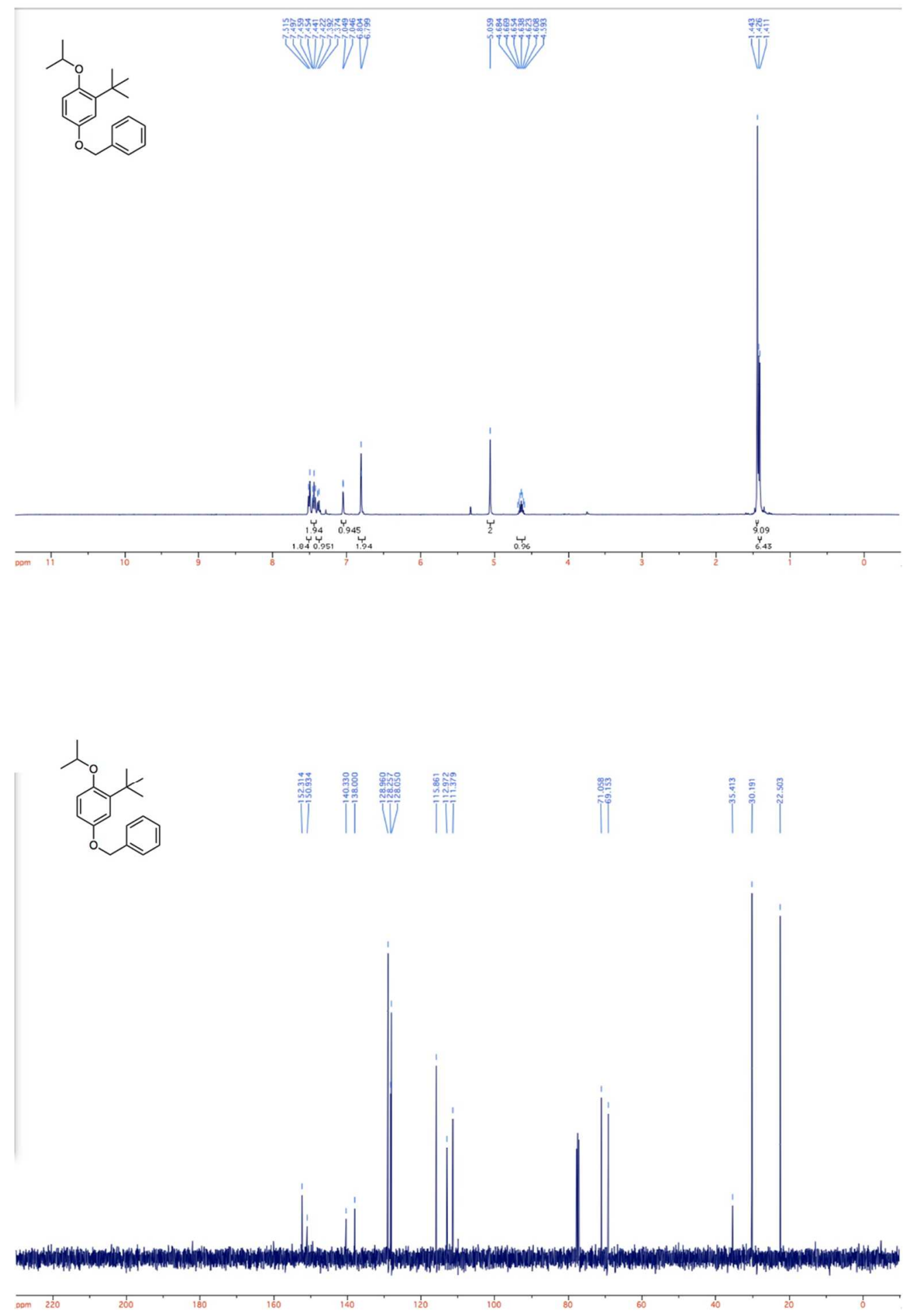

S.I.19 


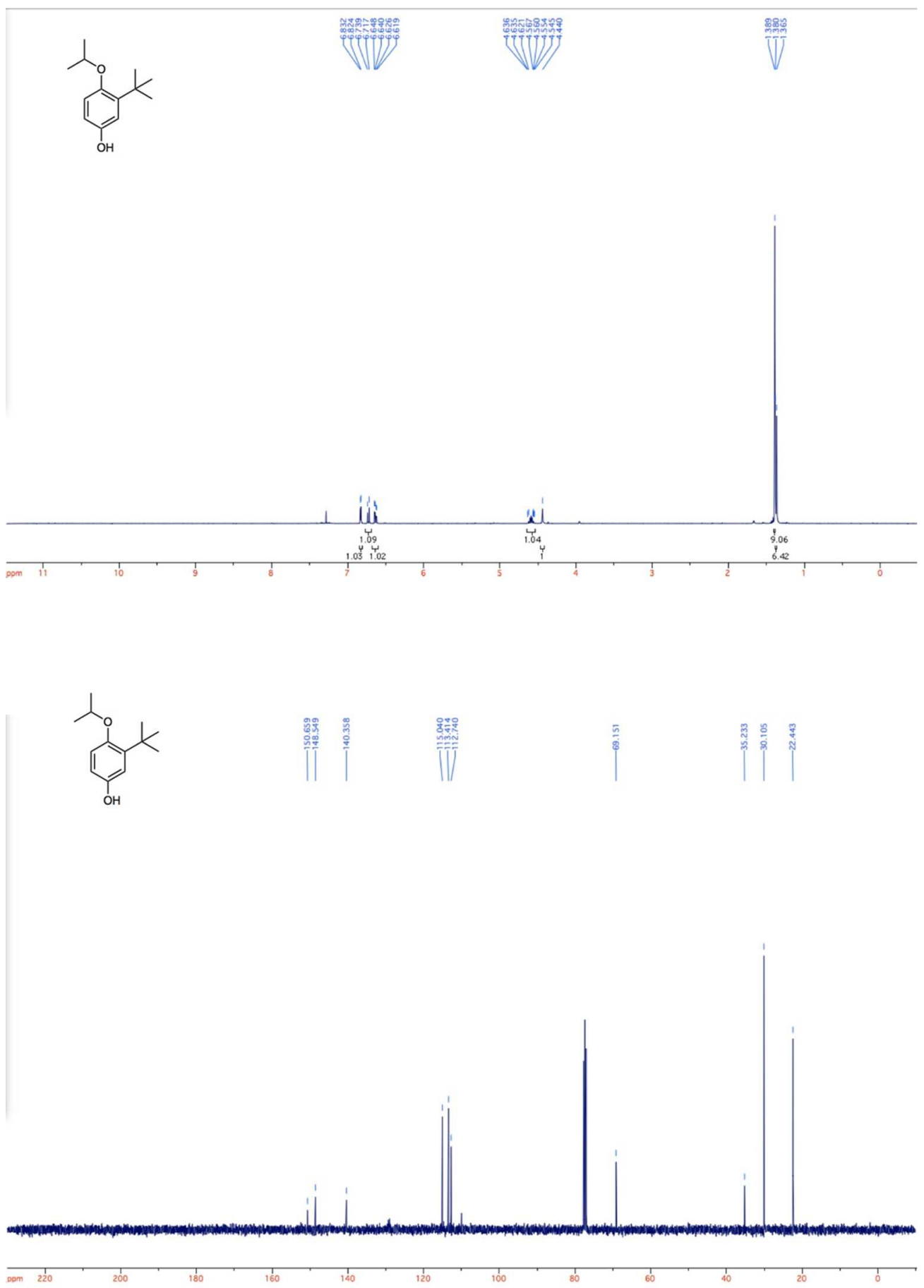

S.1.20 

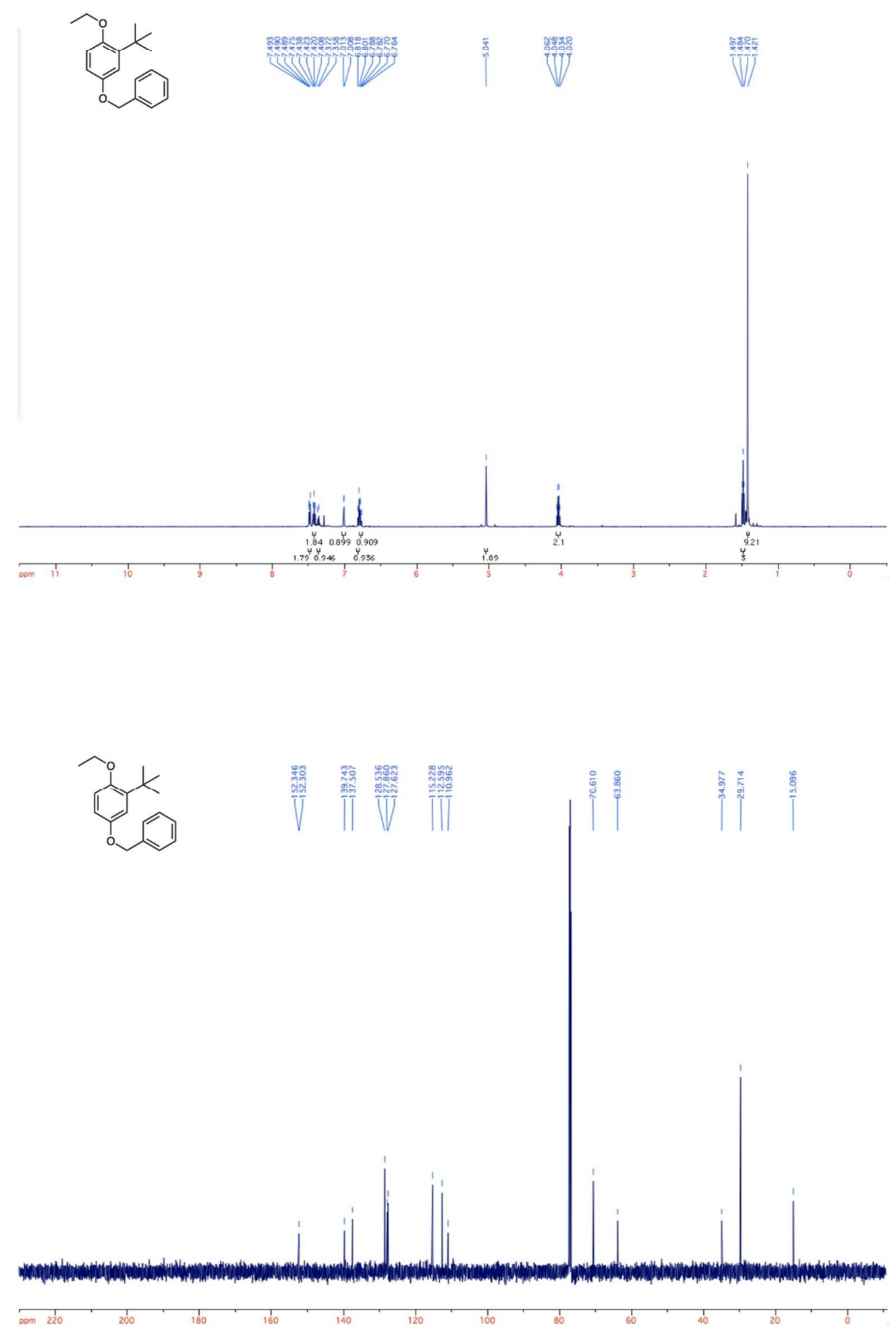

S.I.21 


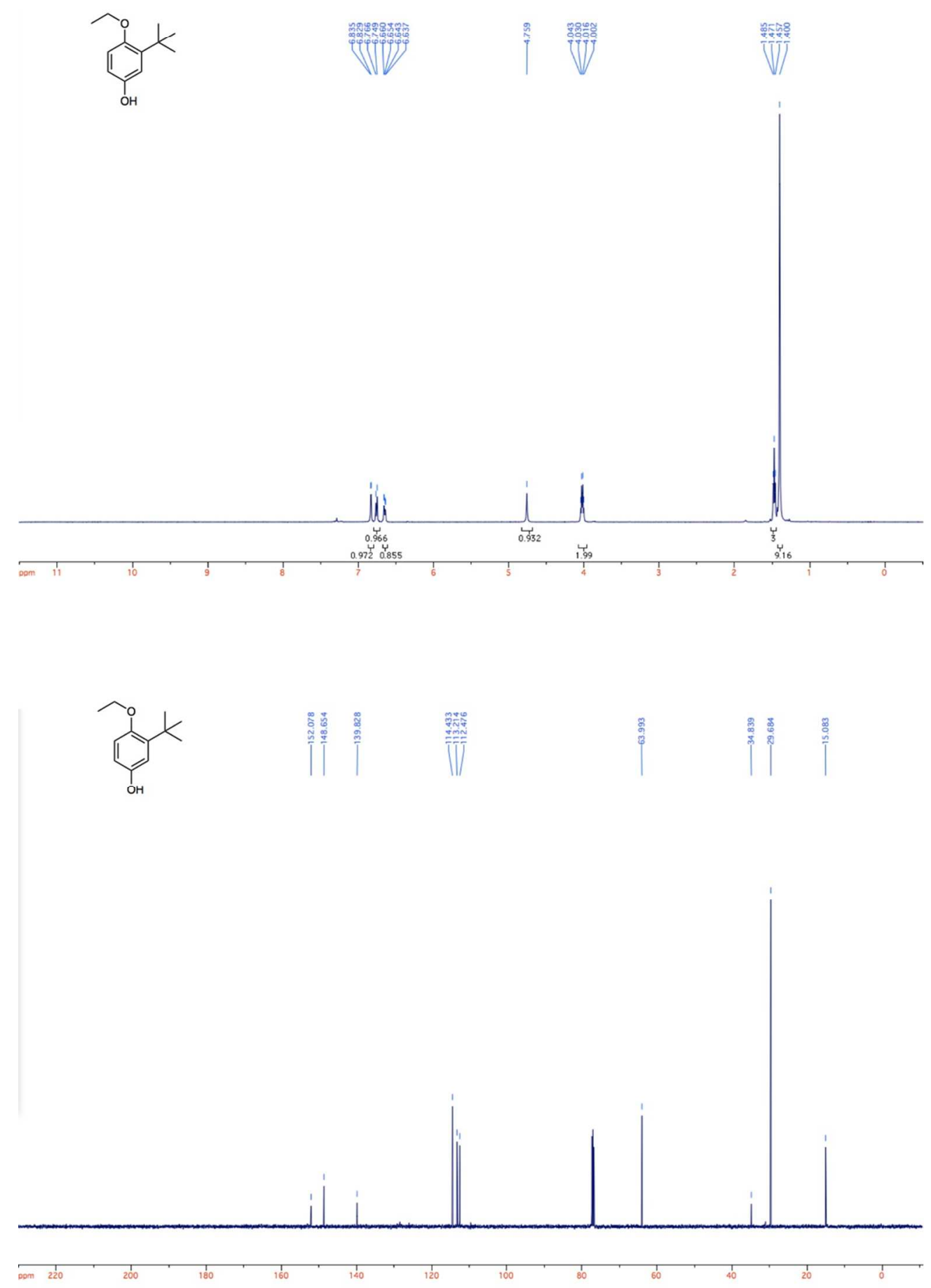

S.1.22 

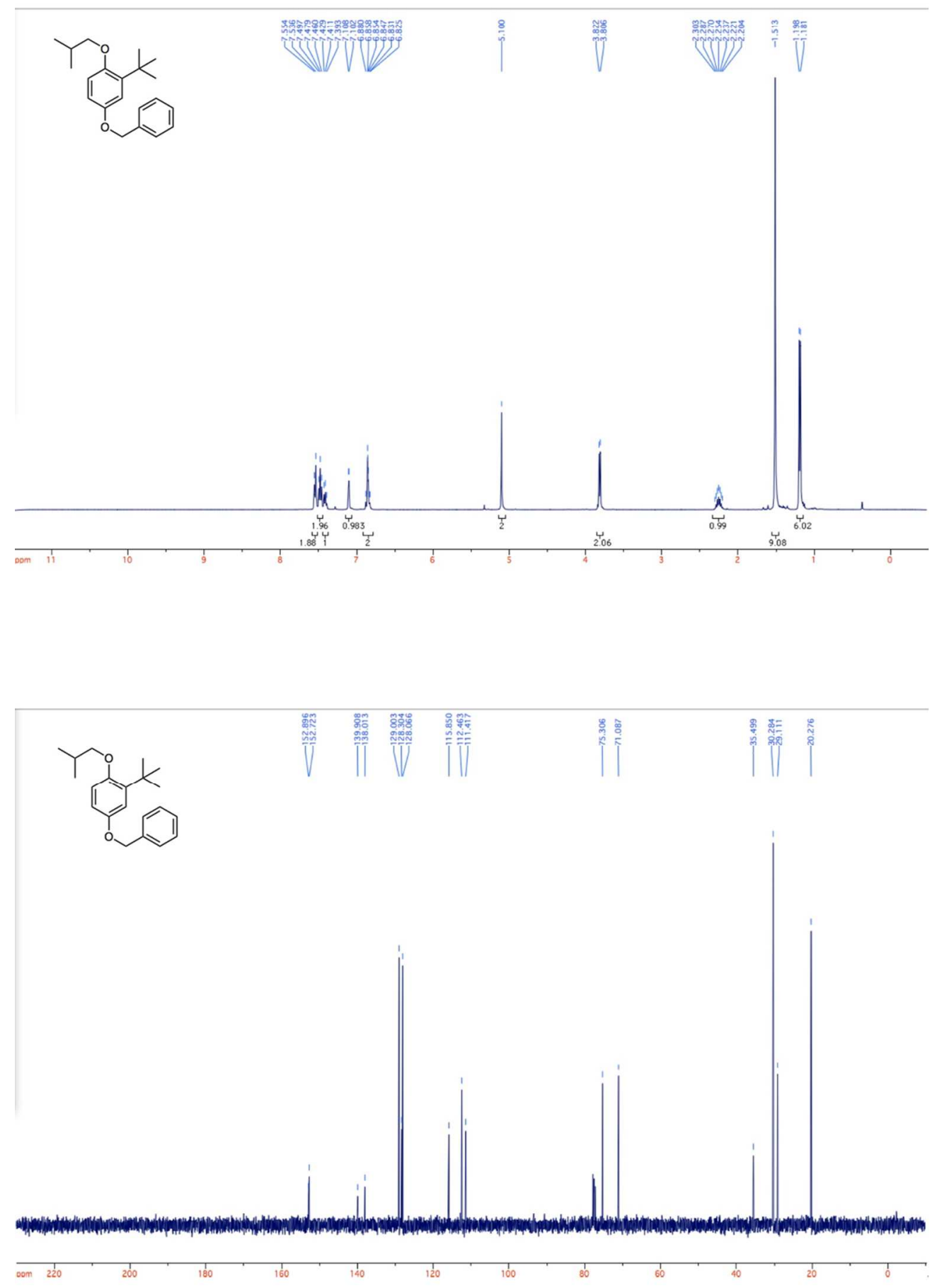

S.I.23 

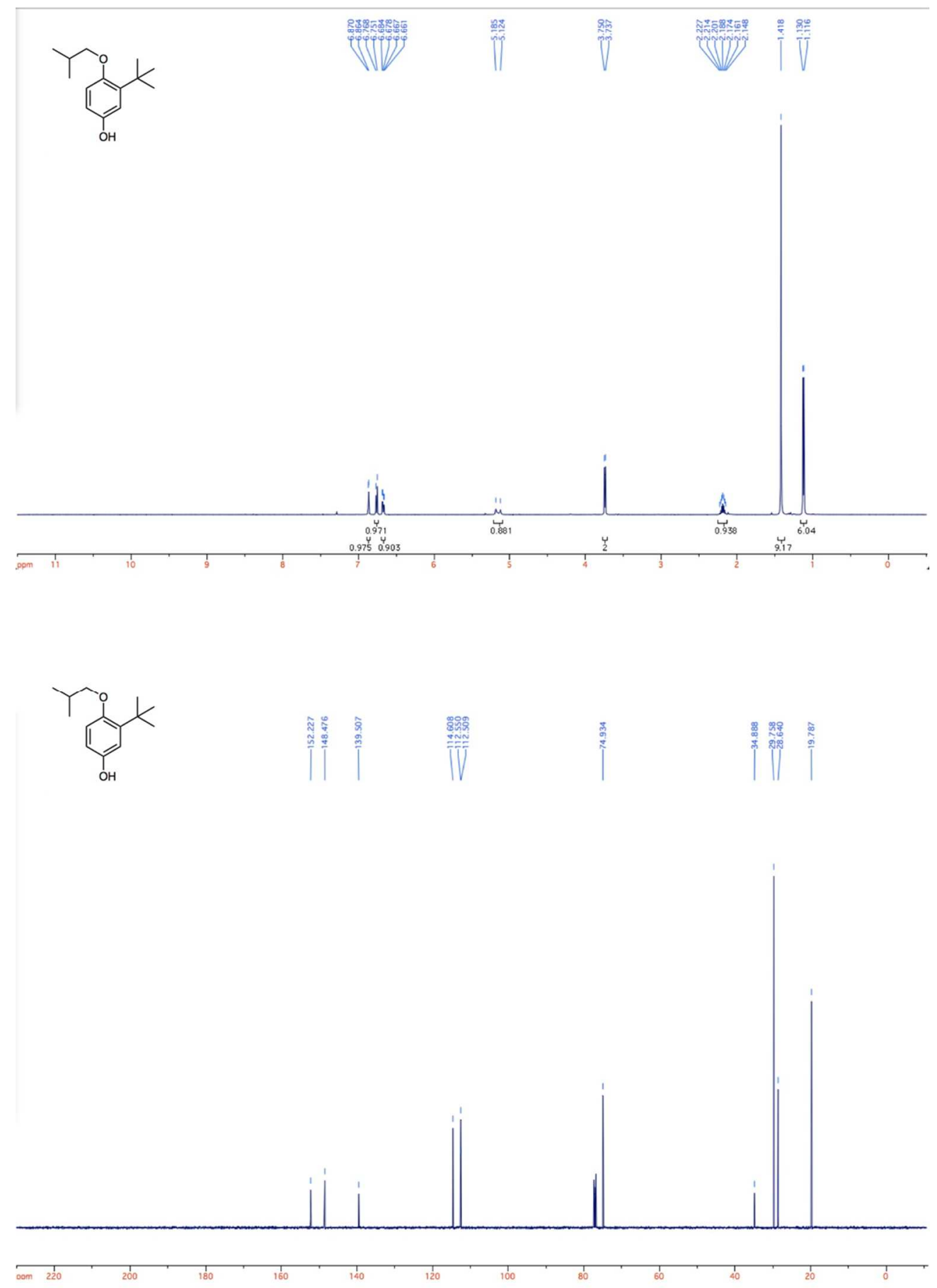

S.I.24 

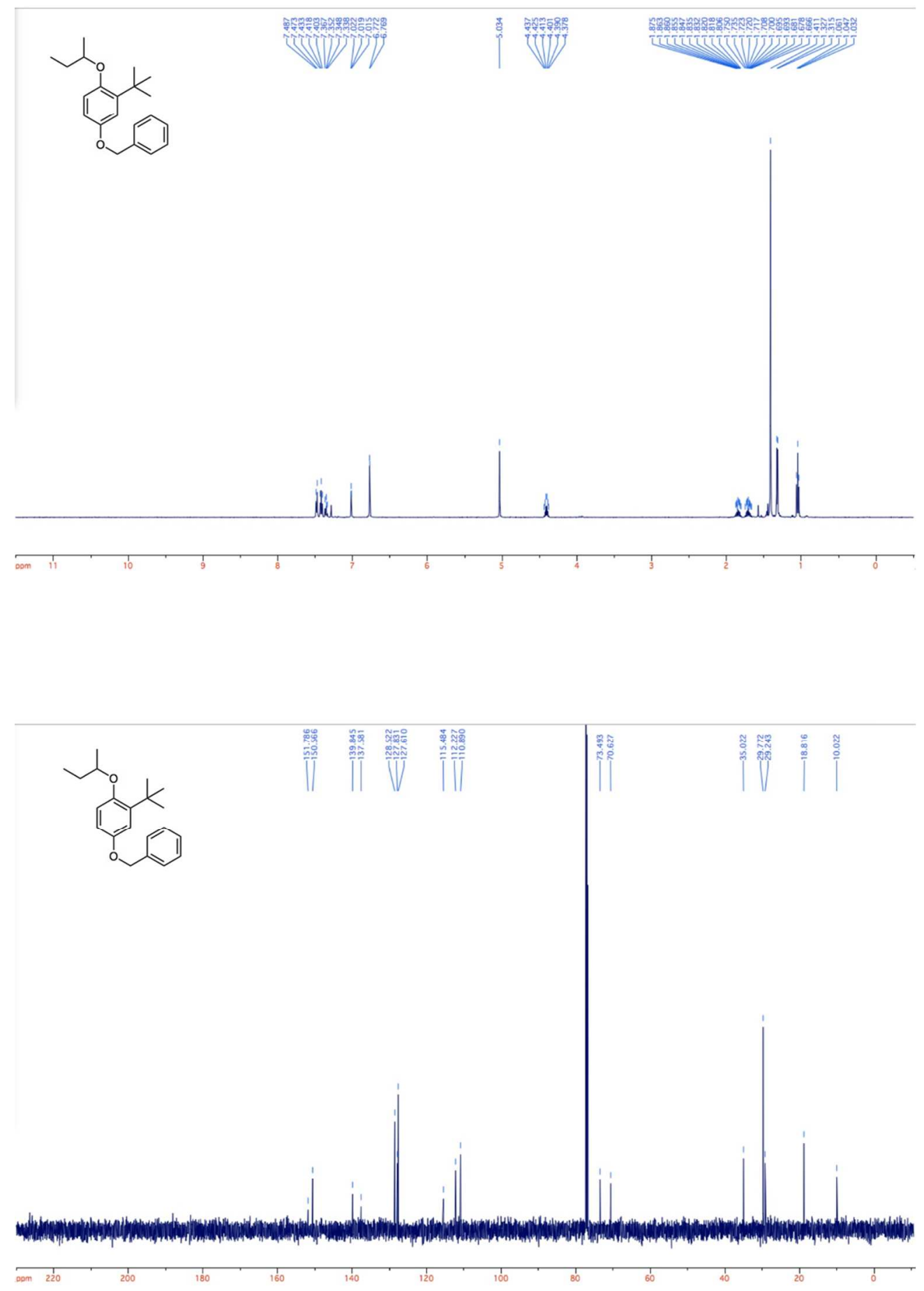

S.I.25 

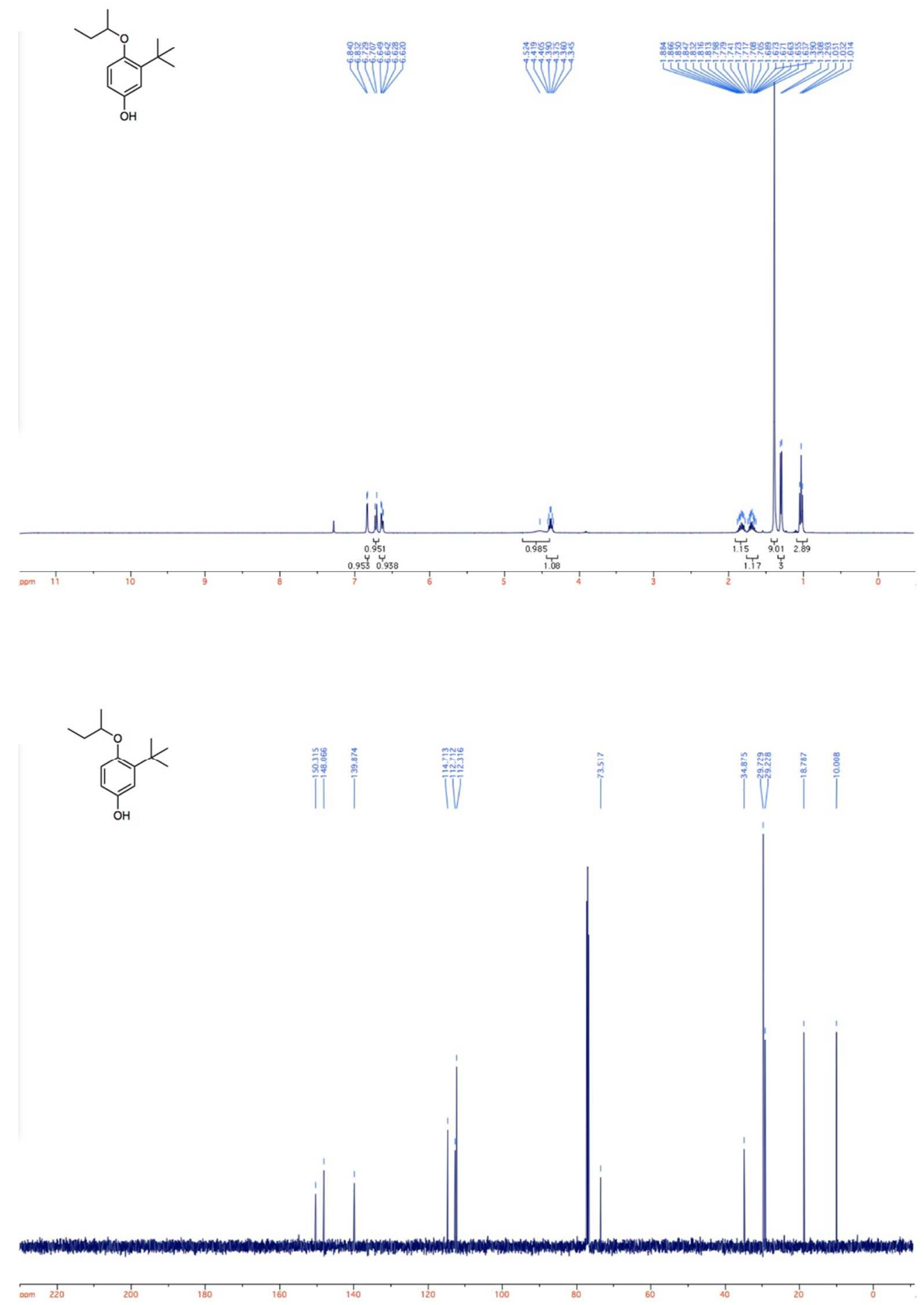

S.1.26 
S.I.27 